\title{
The Effect of Intervention on Nurse's Performance Regarding Feeding of Premature Baby in Neonate Care Unit at Public Hospitals in Hodeida City: Yemen
}

\author{
Hanaa Abduh Heba Mohsen Ebrah*, Kalthoum Ibrahim Yousif \\ Nursing Sciences, Faculty of Nursing Sciences, The National Ribat University, Khartoum, Sudan \\ Email: ^hanaa.ebrah@gmail.com, kalthoumyousif@gmail.com
}

How to cite this paper: Ebrah, H.A.H.M. and Yousif, K.I. (2020) The Effect of Intervention on Nurse's Performance Regarding Feeding of Premature Baby in Neonate Care Unit at Public Hospitals in Hodeida City: Yemen. Open Journal of Pediatrics, 10, 695-706.

https://doi.org/10.4236/ojped.2020.104072

Received: October 12, 2020

Accepted: December 14, 2020

Published: December 17, 2020

Copyright $\odot 2020$ by author(s) and Scientific Research Publishing Inc. This work is licensed under the Creative Commons Attribution International License (CC BY 4.0).

http://creativecommons.org/licenses/by/4.0/

\begin{abstract}
Prematurity is the most common direct cause of newborn mortality that can be reduced by improving the care for premature baby in Neonatal Care Units. Nursing staff working in such units must be highly qualified to avoid complications which lead to the increase of disability and death rate. This study aimed to evaluate the effect of intervention on Nurse's Performance regarding feeding premature baby in Neonate Care Unit. Interventional Study design with pre and posttest was used. The study was carried out at neonatal care units of Organization of AL-Thora Public Hospital and AL-Slkhana Hospital for Maternal and childhood in Hodeida city in Yemen. Method: Total coverage of 50 nurses in the previously mentioned settings. Three tools were used tool viz. the Structured questionnaire including two parts for Demographic data of nurses and level of basic nurse's knowledge tool, the Observation Check list, and the training program procedure which consists of 4 phases: Phase (1) Pretest for the existing knowledge for nurses using the questionnaire format; Phase (2) Orientation to the educational program; Phase (3) close supervision to the participants while applying the nursing practice; Phase (4) Posttest at the end of the program (the same questionnaire and the observation check list format were used). Results: The results showed that the total knowledge and practice skills of the nurses were higher in the posttest than the pretest. There was a statistical significance correlation between the total nurses' knowledge and their total practice's skill in the posttest $(\mathrm{p}<0.05)$. Conclusion: Most of the study participants attained a score less than "good" in the levels of knowledge and practical skills in the pretest which became "very good" to "Excellent" after the educational.
\end{abstract}


Keywords

Hodeida, Premature, Feeding, NCU, Nurse, Pretest, Posttest, Training

Program

\section{Introduction}

One of the greatest challenges is providing adequate nutrition to premature babies, because it is difficult to deliver adequate calories with parenteral nutrition so enteral milk feeds should be introduced as early as a baby can safely tolerate [1].

Although parenteral nutrition provides premature body by protein, fat, carbohydrate, electrolytes, trace elements and vitamins to allow nutritional needs to be met and to optimize growth and also may be required if enteral feeds will not be possible within three days and have a very important role to play in neonatal intensive care, the main disadvantages of it are that it does increase the risk of nosocomial infection, nutrient imbalances and potential toxicity. The most preferred form of nutrition, however, is the enteral with breast milk or expressed breast milk [2].

The health care professional in general and nurses in particular play a vital role to ensure that the premature baby has the best possible beginning of life and the nurse must be aware of the potential problems and be alert to the premature changing condition to intervene appropriately when necessary. The nurse is the first health care provider who has direct contact with premature babies in NICU. Hence nurses require the knowledge and the skills to take care of the babies keeping in mind the basic principles so that many complications can be prevented [3].

NICU nurses should have enough experience in feeding small premature infants, and play an important role to prevent any feeding problem [1].

Consequently, the researcher would like to do an interventional study aiming to evaluate the effect of the training program on the nurses' performance in feeding the pre mature babies in NICU.

\section{Materials and Methods}

\subsection{Study Design}

Interventional Study design with pre and post test was conducted to evaluate the effect of a training program on nurse's performance regarding feeding of premature baby among nurses in neonatal care unit (NCU) at public Hospitals in $\mathrm{Al}$ Hodeida City-January 2018-January 2020.

\subsection{Study Area}

- Organization of AL Thora public Hospital.

- ALSlkhana Hospital for Maternal and childhood. 


\subsection{Data Collection Technique and Tool}

All Qualified nurses who are working in neonatal care unit (NCU) in the assigned hospitals during period of January 2018-January 2020 were involved in the study. A total coverage was taken during the study period (Organization of AL Thora public Hospital are 36 nurses and ALSlkhana Hospital for Maternal and childhood are 14 nurses) Data was collected by a Structured questionnaire constructed by the researcher and validated by expert panel of Pediatricians. The questionnaire includes the demographic data and the questions of the knowledge level of the participants. It is composed of 19 questions each with division from 1 - 6 answer using a scoring system of the phrases (Correct $=1$, incorrect $=0$ ).

The interval scale was used for evaluation of the scores for the level of knowledge items which was evaluated by: poor (0 - 49), acceptable (50 - 59), fair (60 69), good (70 - 79), very good (80 - 89) and excellent (90 - 100).

An observation checks list also constructed by the researcher. It was composed of main 7 observed items each item ranged from 1- 6 parts. The scale used for checklist was scored into (done $=1$, Not done $=0$ ).

\subsection{The Training Program Procedure}

The training program was stated in a time table and was applied in four phases as follows:

Phase One: An Orientation about the program was first given for the participants; the full idea about the phases of application of the program in order to facilitate their contribution.

Pretest for the existing knowledge for nurses was carried out prior to intervention using the questionnaire format; time offered was two hours for all participants (after dividing them to three groups one group in ALSlkhana, two group in ALThora). The time was considered enough time for the participants to answer the questions and was calculated as follows: $(2 \times 3=6$ hour $)$. Pretest for existing skill using the observation check list format was done. Time offered was (one hour and half for each participant to observe the practices and was calculated as follows: ( 1 and $1 / 2 \times 50=105$ hour).

Phase Two: Orientation to the educational program, includes lectures with, the time table, and training materials. The educational program was calculated as follows: ( 3 lectures $\times 2$ hospitals (one of hospital is divided into two groups) $=$ 9 days $=18$ hours).

Lecture time: Each lecture time was one an hour and a half ( 1 and $1 / 2$ hour) and there was about half hour time offered for discussion after each lecture for further clarification about what is missing or not understood by the participants. The breaks times were excluded. The total time of 6 hours to each group (two groups in ALThora hospital and one group in ALSalkhana) which was calculated as follows: $(6 \times 3=18$ hours $)$.

- Intensive training on nursing practice in premature babies feeding was done by using rubber neonate models. The training time was about two hours for each participant (overall time spent for this component was calculated as 
follows: $(2 \times 50=100$ hours $)$.

- After the stimulation on the model baby, the training was continued with real patients for about two hours for each participant. The training calculated as follows: $(2 \times 50=100$ hour $)$.

Phase Three: There was close supervision to the participants while applying the nursing practice in premature babies feeding, their recommendations and protocols on patients during the study period.

Time provided two hours for each participant was calculated as follows: $(2 \times$ $50=100$ hours).

Phase Four: A post-test was obtained from the participants at the end of the program (the same questionnaire and the observation checklist format were used. The time offered for all participant (after dividing to three groups one group in ALSlkhana, two groups in ALThora) was considered enough time for the participant to answer the questions and was calculated as follows: $(2 \times 3=6$ hour $)$.

Total data collection time was calculated and summed as $=435$ hours/6hours a day $=73$ days $/ 20$ days in a month $=3$ months and half which is the total time for data collection.

In order to get the total time spent for the interventional program and the data collection by months, the 435 hours were divided by 6 hours per day which was obtained by 73 days. To be able to obtain the period which was spent per month, according to the feasible time for the researcher (weekends off) to collect the data, the 73 days were divided by 20 days per month in order to reach the total time spent during the study period and it was calculated 3 months $\&$ half.

\section{Ethical consideration}

Application for clearance to conduct the research was submitted to, and approved by the Official letter from the university research committee to all managers of Hospitals under the study was taken for permitting to carry out this research in their hospital.

Ethical approval for this study was received from the manager of NCU in hospital with a focus towards NCU Diploma, BSc and MSc. nurses. Participants were informed by the objectives of the study and their participation was taken by a written consent voluntary.

\section{Problems and Limitations of the study}

The major limitation of this study was material costs and lack of availability of particular side to supports the research, Lack of scientific research published in the area of research in Yemen and the scarcity of scientific references, Full interruption of the Electricity power supply and Temporary interruption of the Internet Network.

\section{Strength of the study}

This research hopefully will improve the nurse's performance regarding feeding of premature baby in neonatal care unit (NCU).

The mother information will be improved when taught by the nurses.

Morbidity \& Mortality will be reduced.

It will be applicable in the Ministry of health hospitals. 


\section{Result}

Description of Respondents: Fifty participated nurses responded to the Questionnaire. All the participants were nurses in the neonatal care unit.

\subsection{Demographic Data}

All participants were young females, $70 \%$ of them had nursing diploma as their higher qualification and most of them (66\%) had nursing experience of 1 - 5 years (Table 1).

\subsection{Results of Nurses Knowledge}

Prior to the educational intervention 50\% of the participants scored "poor" for the correct methods of feeding neonates (Figure 1). This score improved to $92 \%$ in the post-intervention test (Figure 2). Figure 3 shows comparison of the state of knowledge, with clear improvement post educational intervention.

The overall knowledge in various aspects of neonatal feeding improved from a mean score of $53 \%$ prior to the intervention to $95 \%$ after educational sessions, with a $\mathrm{P}$ value of $<0.001$ (Table 2).

Table 1. The frequency distribution of the demographic characteristics.

\begin{tabular}{|c|c|c|}
\hline Characteristics $(\mathrm{N}=50)$ & Frequency & Percentage \\
\hline \multicolumn{3}{|l|}{ Gender } \\
\hline Female & 50 & 100 \\
\hline \multirow[t]{2}{*}{ Male } & 0 & 0 \\
\hline & Age by years & \\
\hline $25-30$ & 38 & 76 \\
\hline $31-35$ & 10 & 20 \\
\hline $36-40$ & 0 & 0 \\
\hline \multirow[t]{2}{*}{$>40$} & 2 & 4 \\
\hline & Education leve & \\
\hline Diploma & 35 & 70 \\
\hline Bachelor & 15 & 30 \\
\hline \multirow[t]{2}{*}{ Master } & 0 & 0 \\
\hline & Experience & \\
\hline $1-5$ Years & 33 & 66 \\
\hline $6-10$ Years & 15 & 30 \\
\hline \multirow[t]{2}{*}{ more than 10} & 2 & 4 \\
\hline & Training Cour & \\
\hline No & 26 & 52 \\
\hline Yes & 24 & 48 \\
\hline
\end{tabular}




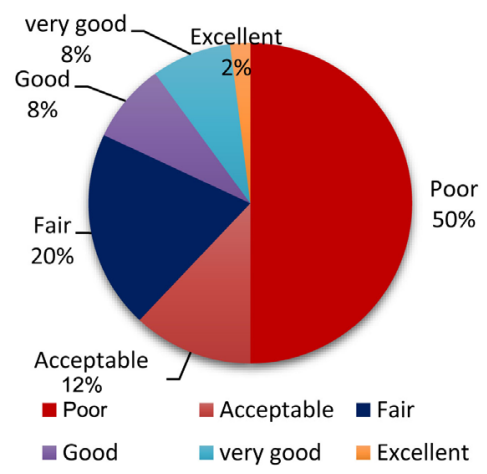

Figure 1. The levels of Knowledge among nurses participating in the study prior the esducational intervention.

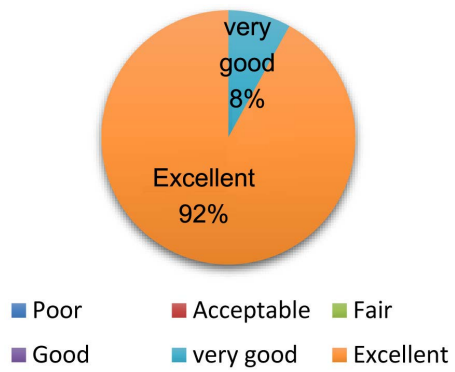

Figure 2. The levels of Knowledge among nurses participating in the study after the educational intervention.

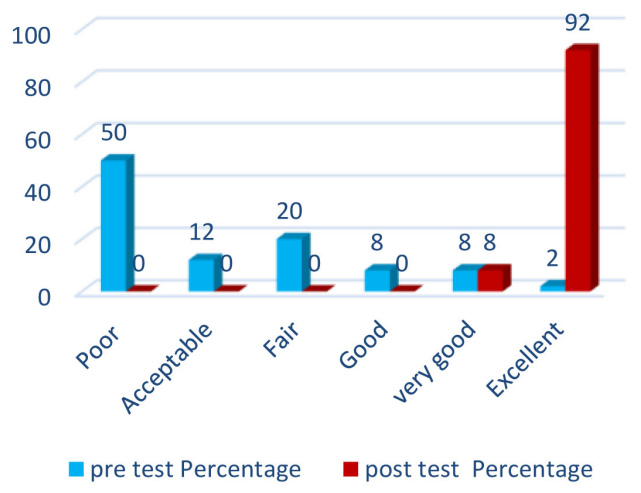

Figure 3. Comparison between the levels of Knowledge among nurses participating in the study pre and post the educational intervention.

Table 2. Overall score of nurses' knowledge prior to and after the educational intervention.

\begin{tabular}{rrrrcrr}
\hline \multicolumn{2}{c}{ Knowledge total scores } & Mean & N & Std. Deviation & T-test & P-value \\
\hline \multirow{2}{*}{ Pair 1 } & Pre test & 53.5200 & 50 & 17.39486 & & \\
& Post test & 95.10 & 50 & 3.632 & 17.154 & $<0.001$ \\
\hline
\end{tabular}

With respect to the level of nurses' qualifications both Diploma and Bacheolar holders had approximately similar levels of knowledge prior to the educational intervention and improved post intervention (Table 3). 
Table 3. Correlations between the Level of qualification and the knowledge of the nurses pre and post intervention.

\begin{tabular}{|c|c|c|c|c|c|c|}
\hline \multicolumn{2}{|c|}{$\begin{array}{c}\text { Descriptive } \\
\text { Level of qualification }\end{array}$} & \multirow{2}{*}{$\begin{array}{l}\mathrm{N} \\
35\end{array}$} & \multirow{2}{*}{$\begin{array}{c}\text { Mean } \\
50.9143\end{array}$} & \multirow{2}{*}{$\begin{array}{c}\text { Std. Deviation } \\
18.08212\end{array}$} & \multirow[t]{2}{*}{ F test } & \multirow[t]{2}{*}{$P$ value } \\
\hline & Diploma & & & & & \\
\hline \multirow[t]{3}{*}{ Pre test } & Bachelor & 15 & 59.6000 & 14.43607 & 2.709 & 0.106 \\
\hline & Total & 50 & 53.5200 & 17.39486 & & \\
\hline & Diploma & 35 & 94.46 & 3.928 & & \\
\hline \multirow[t]{2}{*}{ Post test } & Bachelor & 15 & 96.60 & 2.293 & 3.868 & 0.055 \\
\hline & Total & 50 & 95.10 & 3.632 & & \\
\hline
\end{tabular}

Table 4 shows the correlation between the participants who had experience for $1-5$ years with those who had 6 - 10 years of experience. In the pre test stage of the study the more experienced nurses did a lot better ( $\mathrm{P}$ value 0.006 ); but in the post test stage there was no significant difference between the two groups.

\subsection{Results of Nurses Practices}

The overall practical skills in various aspects of neonatal feeding improved from a mean score of $42 \%$ prior to the intervention to $97 \%$ after the training sessions, with a $\mathrm{P}$ value of $<0.001$ (Table 5).

With regard to the practical skills, $74 \%$ of the participants attained poor score prior to the training sessions (Figure 4) then the level of the practical skills improved to $94 \%$ (Figure 5).

The comparison between the two stages is depicted in Figure 6, Table 6 shows the correlation in practical skills between the participants who had experience for 1 - 5 years with those who had 6 - 10 years of experience. In the pre test stage of the study the more experienced nurses did a lot better ( $\mathrm{P}$ value 0.0 .002$)$; but in the post test stage there was no significant difference between the two groups.

\subsection{Correlations between Knowledge and Practice Skill}

The correlation between the pre test practical skill and the pretest level of knowledge showed no correlation while the post test for the practical skills and the post test level of knowledge showed significant correlation P value 0.001 (Table 7).

\section{Discussion}

The demographic characteristics of the current study show that the majority of participants (76\%) are between 25 - 30 years old Similar findings were reported by a study in Sudan which showed that the majority of NICU nurses (60\%) years. [4] The young age with hyperactivity was required in such a critical area. Hundred percent of the participants were female. Similar findings were reported by a study in Sudan which showed that all the pediatric nurses (100\%) in the unit are female which can be attributed to the hospital polices that women have 


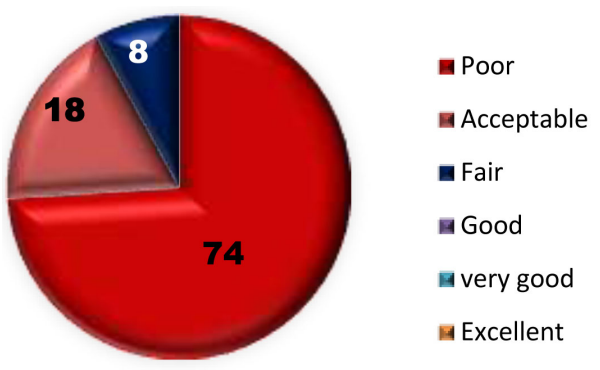

Figure 4. The levels of practical skills among nurses participating in the study prior the educational intervention.

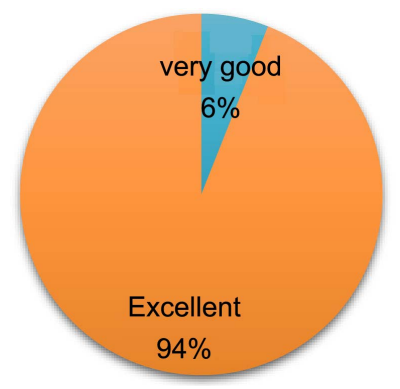

Figure 5. The levels of practical skills among nurses participating in the study after the educational intervention.

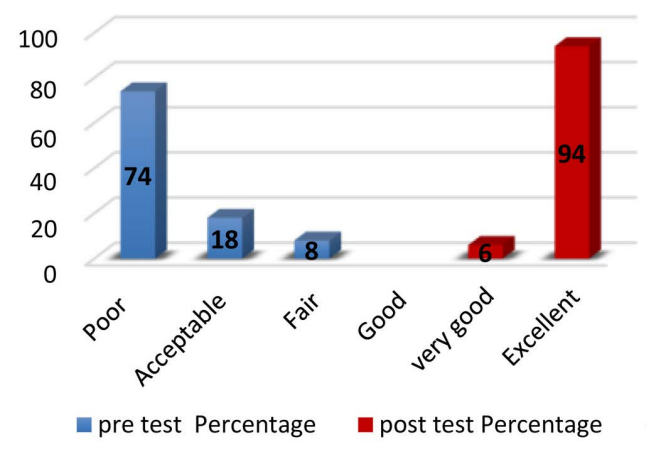

Figure 6. Comparison between the levels of practical skills among nurses participating in the study pre and post the educational intervention.

Table 4. Correlations between the years of experience and the knowledge of the nurses in the pre and post intervention.

\begin{tabular}{ccccccc}
\hline \multicolumn{2}{c}{$\begin{array}{c}\text { Descriptive } \\
\text { years of experience }\end{array}$} & $\mathrm{N}$ & Mean & Std. Deviation & F test & P value \\
\hline \multirow{4}{*}{ Pre test } & 1 - 5 Years & 33 & 48.3030 & 16.46110 & & \\
& 6 - 10 Years & 15 & 62.2000 & 15.08642 & & \\
& more than 10 & 2 & 74.5000 & 7.77817 & & 0.006 \\
& Total & 50 & 53.5200 & 17.39486 & & \\
\multirow{3}{*}{ Post test } & $1-5$ Years & 33 & 94.94 & 3.240 & & \\
& 6 - 10 Years & 15 & 94.93 & 4.448 & \multirow{2}{*}{1.211} & 0.307 \\
& more than 10 & 2 & 99.00 & 1.414 & & \\
\hline
\end{tabular}


Table 5. Effect of the educational program on nurses' overall practice skills prior to and after the educational intervention.

\begin{tabular}{ccccccc}
\hline \multicolumn{2}{c}{ practice skills total scores } & Mean & N & Std. Deviation & t test & P value \\
\hline \multirow{2}{*}{ Pair 1 } & Pre test & 42.98 & 50 & 11.149 & & \\
& Post test & 97.20 & 50 & 3.156 & 33.097 & 0.001 \\
\hline
\end{tabular}

Table 6. Correlations between Level of experience and practice skills pre and post intervention.

\begin{tabular}{cccccc}
\hline \multirow{2}{*}{ Experience } & Mean & Std. Deviation & F test & P value \\
\hline \multirow{3}{*}{ Per test } & $1-5$ Years & 39.73 & 10.657 & & \\
& 6 - 10 Years & 47.53 & 8.576 & 7.159 & 0.002 \\
more than 10 & 62.50 & 2.121 & 11.149 & & \\
Post test & Total & 42.98 & 3.326 & & 0.442 \\
& 1 - 5 Years & 96.81 & 2.908 & & \\
& 6 - 10 Years & 97.80 & 9.000 & & \\
\hline
\end{tabular}

Table 7. Correlations between pre and post score in Knowledge and pre post score in practice skills.

\begin{tabular}{|c|c|c|c|c|c|}
\hline \multicolumn{2}{|c|}{ Correlations } & \multirow{2}{*}{$\begin{array}{c}\text { Post test score } \\
\text { practice } \\
1\end{array}$} & \multirow{2}{*}{$\begin{array}{c}\begin{array}{c}\text { Pretest score } \\
\text { practice }\end{array} \\
0.371^{\star *}\end{array}$} & \multirow{2}{*}{$\begin{array}{c}\begin{array}{c}\text { Pretest score } \\
\text { knowledge }\end{array} \\
0.175\end{array}$} & \multirow{2}{*}{$\begin{array}{c}\begin{array}{c}\text { Post test score } \\
\text { knowledge }\end{array} \\
0.009\end{array}$} \\
\hline Post tect score & $\begin{array}{l}\text { Pearson } \\
\text { Correlation }\end{array}$ & & & & \\
\hline practice & Sig. (2-tailed) & & 0.009 & 0.228 & 0.950 \\
\hline & $\mathrm{N}$ & 49 & 49 & 49 & 49 \\
\hline \multirow{3}{*}{$\begin{array}{c}\text { Pretest score } \\
\text { practice }\end{array}$} & $\begin{array}{l}\text { Pearson } \\
\text { Correlation }\end{array}$ & & 1 & $0.561^{* *}$ & -0.107 \\
\hline & Sig. (2-tailed) & & & 0.000 & 0.458 \\
\hline & $\mathrm{N}$ & & & 50 & 50 \\
\hline \multirow{3}{*}{$\begin{array}{l}\text { Pretest score } \\
\text { knowledge }\end{array}$} & $\begin{array}{l}\text { Pearson } \\
\text { Correlation }\end{array}$ & & & 1 & 0.174 \\
\hline & Sig. (2-tailed) & & & & 0.226 \\
\hline & $\mathrm{N}$ & & & & 50 \\
\hline $\begin{array}{l}\text { Posttest score } \\
\text { knowledge }\end{array}$ & $\begin{array}{l}\text { Pearson } \\
\text { Correlation }\end{array}$ & & & & 1 \\
\hline
\end{tabular}

${ }^{* *}$ Correlation is significant at the 0.01 level (2-tailed).

a sense of mother naturally [5]. Regarding the level of education, it is observed in this study that $(70 \%)$ of nurses have a diploma degree, which matches with Basha study in Yemen that showed that only (83\%) have diploma degree [6]. This is considered as a very serious indicator in Yemen that most of the staff are not qualified academically enough to bear their responsibilities as required. Two third of the participants had $1-5$ years of experience. It is believed that the con- 
ditions of conflict in Hodieda have led to the leaving and escaping the foreign countries and local expertise of nursing staff are curing the health care for NICU. About the training courses, it found that (52\%) of nurses do not have any training courses in neonatal care. This result is congruent with the results reported by a study in Sudan in which (56\%) of nurses do not have any training course in neonatal care units [5].

The general knowledge of nurses prior to the educational interventions scores for less than "good" then improved to "very good" and "excellent" post the educational intervention, (Figure 3).

The current study findings seem to be consistent with Punjab study which reported that the majority of nurses had less than "good" in the pretest. While in the post test it was observed that (83.8\%) of the sample had good and excellent level of knowledge after teaching program regarding care of low birth weight baby [7]. Moreover, the current result is with agreement with other Egypt research which found the entire sample (100\%) is less than good of knowledge in the pretest. On the other hand, nurses' knowledge improved to be good by majority of the nurses (93.3\%) when testing their knowledge in preventing premature babies' hypothermia [5]. There was a highly statistically significant difference in the overall level of knowledge at $P$ value $=0.000$ (Table 2).

The result of current the study is similar with the findings in Florida study which reported that there is a significant, positive difference in the knowledge of nurses after an educational intervention [8]. The current study's results are also in consistent with data obtained in Punjab study which showed that a $\mathrm{P} \leq 0.05$ level of significance. As a result, there was an impact of structured teaching program on knowledge regarding Care of low birth weight baby [7]. In contrast with Iraq study findings the participants had a good level of knowledge where the mean of scores they got was about $74 \%$, all are knowledgeable nurses because they all passed the evaluation knowledge (succeed) in Management of Premature Baby in Neonatal Units [9].

With regards to the correlation between the level of the nurses' knowledge and the years of experience: Table 4 correlates between the years of experience and the knowledge of the nurses, which revealed that there is statistically significant relationship between the years of experience and the knowledge in the pretest $\mathrm{P}$ value $=0.006$, but in the post test there is no statistically significant. These result are in line with Punjab study which showed that in the clinical experience years in-service education program had non-significant association [7]. In contrast with Iraq study findings which showed that there is significant correlation between the scores the nurses and the years of their experiences. However, there is no significant correlation between the scores the nurses and the level of education in the same study as well [9].

Figure 4 displays the practical skills of the nurse's prior the educational interventions. In which the participants attained a score of practical skills less than "good". All the fifty nurses (100\%) attained a score of "very good" to "Excellent" 
after the educational intervention (Figure 5). The comparison between the pre and post intervention scores was shown in (Figure 6). However, the findings of the current study are higher than two Egyptian previous researches, in which the first study showed that most of nurses (96.7\%) at pretest had incompetent performance to prevent hypothermia in preterm infants while, in the post-test the majority of nurses (85\%) became competent in their performance [10]. The 2nd study reported the nurses' performance according to total score $(70.49 \%)$ of all nursing procedure in infection control before intervention they had unsatisfactory grade compared with two-thirds of them (63.39\%) who attain good result. But (21.31\%) were satisfactory in their performance after intervention [11].

Table 5 shows the effect after the educational program on the nurses' overall cumulative practical skills, where there was a clear improvement in the level of expertise in handling various aspects of feeding premature that attained a highly significant difference at $\mathrm{P}=0.000$. Regarding the correlation between the level of nurses' practical skills and Level of qualification (Table 6) it showed no statistical significant relationship $P$ value $>0.05$.

the correlations between the level of experience and the practical skills (Table 7), It showed the overall mean practical skills score between paired samples pre-intervention and post intervention with a statistically significant relationship.

There is a positive Pearson Correlation ( 0.01 level) between the nurse's knowledge scores and the practical skills. These results are in agreement with those obtained by Egypt study which reported that there was a statistical significant correlation between nurses' total knowledge about neonatal hypothermia and their performance in the pre, post and follow up test [10]. The study shows that there are significant differences $P$. value $<0.001$ in knowledge, practice and the variables of the educational level, training courses and the real period of working in the baby units [12].

Overall mean knowledge score between the paired samples pre-intervention was found to be highly significant with a $\mathrm{P}$ value $<0.000$ in all aspects. Over all mean practice skills score between the paired samples pre-intervention found to be improved in the post test and a $\mathrm{P}$ value $<0.000$.

\section{Conclusion}

The majority of them are with experience less than 5 years. Most of them attained a score less than "good" in the levels of knowledge and practical skills which became "very good" to "excellent" after the educational intervention. There is highly statistically significant relationship between years of experience, knowledge and practical skills.

\section{Acknowledgements}

In this study, my acknowledgement will be directed to all nurses in the assigned hospitals who helped me in conducting this study and to everybody facilitate this 
work to me.

\section{Conflicts of Interest}

The authors declare no conflicts of interest regarding the publication of this paper.

\section{References}

[1] UNICEF and WHO (2018) Neonatal Care Clinical Guidelines. World Health Organzation and UNICEF: The Kingdom of Eswatini. 180.

[2] McKie, J., et al. (2014) Neonatal Unit Handbook.

[3] Abdulfattah, N. and A.E.D. Negawa, Z. (2012) Assessment of Quality of Nursing Care Provided Immediately after Birth at University Hospital. Life Science Journal, 9, 2115-2126.

[4] Babeker, Z.A. (2015) Assessment of Nurse's Knowledge and Practice Regarding Care of Premature Baby in Neonatal Intensive Care Unit at Omdurman Maternity Hospital and Alribat University Hospital, in Pediatric Nursing. The National Ribat University, Faculty of Graduate Studies \& Scientific Research. 62.

[5] Moula, W. and Kambal, I. (2016) Pediatric Nurses' Knowledge and Practices Regarding Nursing Management of Premature Babies in Neonatal Intensive Care Unit at Soba University Hospital, Khartoum State, Sudan. International Journal of Recent Research in Life Sciences, 3, 1-9.

[6] Bash, N. (2016) Patterns of Nursing Knowledge in Identification of Neonatal Sepsis in NCU. Nursing Department, Sanaa University, Sana'a.

[7] Kaur, R. (2013) Staff Nurses (NICU) Knowledge Regarding Care of Low Birth Weight Baby. IOSR Journal of Nursing and Health Science, 1, 1-4. https://doi.org/10.9790/1959-0130104

[8] Onyejuruwa, F.I. (2014) Impact of an Educational Intervention on Nurses' Knowledge and Caring Behavior for Late Preterm Infants. Florida Atlantic University, Boca Raton, Florida.

[9] Issa, S.S., Madwah, K.J.A. and Al Mosawi, H.S. (2018) Evaluation of Nurse's Knowledge in Management of Premature Baby in Neonatal Units. American Journal of Nursing, 6, 291-295. https://doi.org/10.12691/ajnr-6-5-10

[10] Abdel Rasoul, G., et al. (2017) Effect of Designed Guidelines on Nurses' Performance to Prevent Preterm Infants' Hypothermia.

[11] Elsyed, E.M., Zahran, S.A. and Elawany, T.A. (2008) Effect of Educational Intervention on Nurses Performance to Control Infection in Neonatal Intensive Care Unit Tanta University Hospital. Journal of High Institute of Public Health, 38, 509-526. https://doi.org/10.21608/jhiph.2008.20901

[12] Al Zbedee, M.A.G. (2005) Assessing the Nursing Knowledge and Practices in Premature Feeding in Premature Units. Nursing Department, AL-Mosul University, AL-Eraq. 